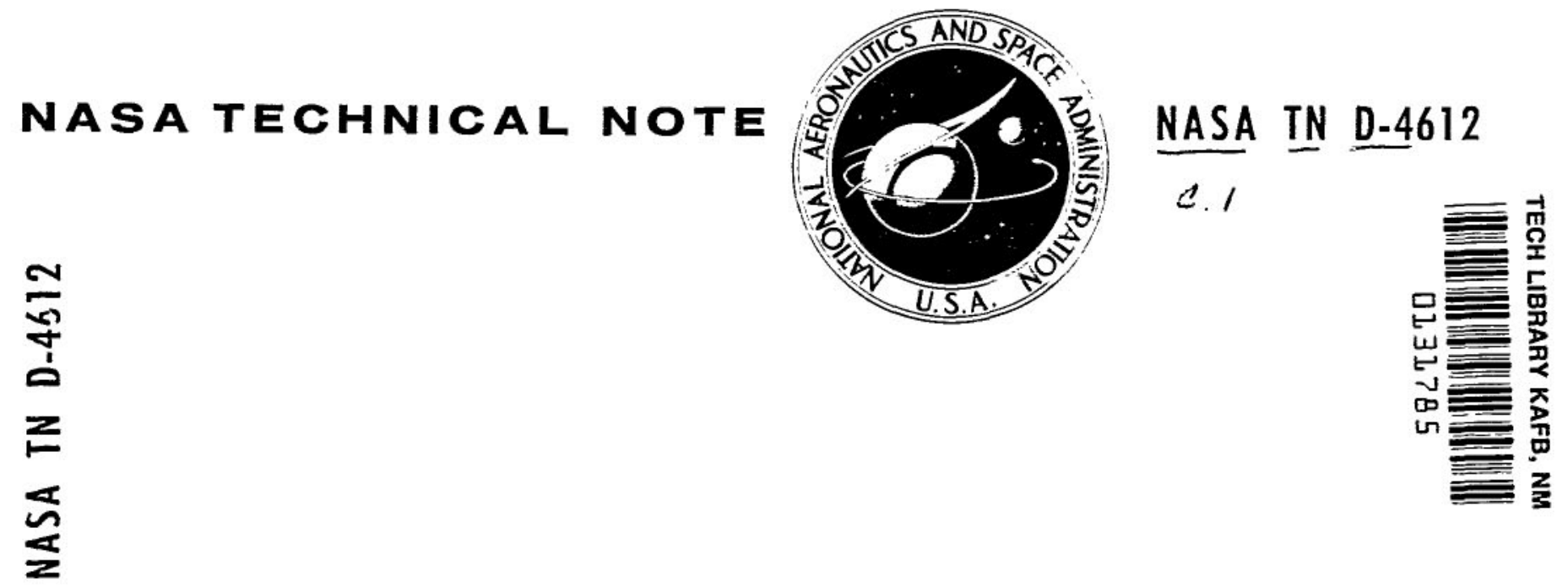

LOAN COPY: RETURN TO AFWL (WLIL-2) KIRTLAND AFB, N MEX

\title{
MONOMOLECULAR CONTAMINATION OF OPTICAL SURFACES
}

by H. Shapiro and J. Hanyok

Goddard Space Flight Center

Greenbelt, $\mathrm{N} I$.

national aeronautics and SPACE administration - WaShington, D. C. • JUNE 1968

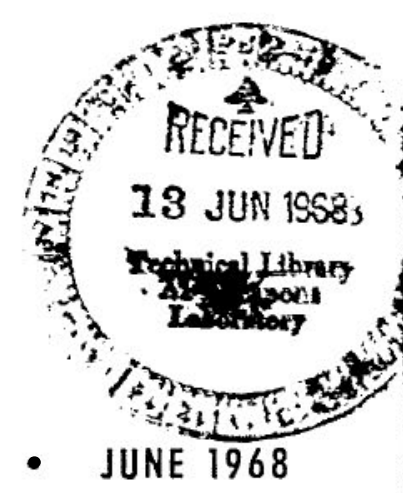


MONOMOLECULAR CONTAMINATION OF OPTICAL SURFACES

By H. Shapiro and J. Hanyok

Goddard Space Flight Center

Greenbelt, Md.

NATIONAL AERONAUTICS AND SPACE ADMINISTRATION

For sale by the Clearinghouse for Federal Scientific and Technical Information Springfield, Virginia 22151 - CFSTI price $\$ 3.00$ 


\begin{abstract}
This paper describes the measurement of ultraviolet reflectance change in mirrors, caused by oil contamination. Spacecraft equipped with such mirrors are tested in a vacuum generated by oil diffusion pumps, the oil being DC 704 ("tetramethyltetraphenyltrisiloxane"). Within instrumental limits, our experimental mirrors show no change in reflectivity when the vacuum chamber is operated in the usual mode. Contamination is plotted against amount of oil deposited, the amount being measured by a quartz-crystal microbalance. The observed phenomena give a more complete picture of the contamination process than existed previously. Deposited oil, it is found, forms minute droplets on the surface of mirrors coated with $\mathrm{MgF}_{2}$. The droplets can be evaporated from the surface at a much higher chamber pressure than the rated vapor pressure of the bulk liquid; this provides a way of cleaning the mirrors. It is possible to operate diffusion-pumped systems so as to minimize contamination.
\end{abstract}


CONTENTS

Abstract. . . . . . . . .

INTRODUCTION. ................. 1

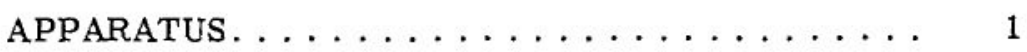

EXPERIMENTAL PROCEDURES $\ldots \ldots \ldots \ldots \ldots$

DISCUSSTON AND CONCLUSIONS. . . . . . . . . 14

References . . . . . . . . . . . . 16

Appendix A-Quartz Crystal Microbalance ...... 17 


\title{
MONOMOLECULAR CONTAMINATION OF OPTICAL SURFACES
}

\author{
by \\ H. Shapiro and J. Hanyok \\ Goddard Space Flight Center
}

\section{INTRODUCTION}

The word "contaminate" as used in this paper means to make unfit for use by the introduction of undesirable elements. This paper considers the undesirable element to be backstreaming diffusion pump oil, specifically DC 704, and the desirable element to be a mirrored surface. There are no established standards that define the term "unfit," especially as it pertains to aerospace applications. Those who test spacecraft or their subsystems are frequently warned not to contaminate the mirror systems with backstreaming oil. "Degradation" (defined as the diminution of reflectivity at $1216 \AA$ after exposure to vacuum) is nowadays tolerated if under 5 percent.

DC 704 oil (tetramethyltetraphenyltrisiloxane) has a molecular weight of 484 and an effective molecular size of $12 \hat{\AA}$ : hence, a monomolecular layer on a $25-\mathrm{cm}^{2}$ mirror weighs approximately $1.3 \cdot 10^{-6} \mathrm{gm}$. Experience gained in the course of building a quartz crystal microbalance, permitted quantities as small as $10^{-9} \mathrm{gm}$ to be measured. This instrument seems ideal as a contamination monitor since the accommodation coefficients of quartz and $\mathrm{Mg} \mathrm{F}_{2}$ are not known to be radically different. The instrument is small and can be used as a monitor over the pressure range from ambient through the vacuum region and back to ambient. Continuous readings are possible. In addition, the results can be checked for total weight by using sufficiently large deposition areas and a standard laboratory microbalance. Mirrors were measured for reflectivity before and after exposure, using a vacuum ultraviolet spectrophotometer at $1216 \AA$ with a hydrogen lamp as the source. During the course of this research, a number of interesting phenomena were observed and explored. These will be described later. Finally, the main object of this work is arrived at: a graph of percentage mirror degradation versus DC 704 contamination.

\section{APPARATUS}

The vacuum equipment consists of a 24- . 30-inch stainless steel cylinder pumped by a 10-inch diffusion pump and a 4 -inch booster pump: the system is backed by a $350-\mathrm{cfm}$ mechanical pump. Between the diffusion pump and the vacuum side, there is a water baffle and a liquid-nitrogen baffle. all commercially available. A stainless-steel cell with two 25 -watt resistors cemented to 
its sides generated oil vapor. Mirrors were of $2-\times 2$-inch, plate-glass substrate coated with evaporated aluminum and overcoated with $\mathrm{MgF}_{2}$ to allow rougher handling and permit examination at $1216 \AA$. The mirror was suspended in the same plane as, and adjacent to, the crystals of a quartz crystal microbalance (described in Appendix A). Verification of the microbalance calibration and of some of the data was performed with a commerical, single-pan microbalance, whose averaged readings were assumed to be correct. Microscopy was performed with a metallographic microscope with monochromatic illumination in the blue. Electron microscopy was performed with a Cambridge scanning electron microscope.

\section{EXPERIMENTAL PROCEDURES}

Mirrors and crystals were suspended in the same plane, approximately 18 inches above the $\mathrm{LN}_{2}$ trap of a 10-inch diffusion pump. Mirrors were measured at $1216 \AA$ before exposure to the vacuum and remeasured at the same wavelength after exposure, together with a control mirror, which remained exposed to the laboratory air. After the crystals and mirrors were mounted, the chamber was closed; a base line for the microbalance was established; then pumpdown with the mechanical pump proceeded. At this point, the base line indicated a decrease in weight, which was attributed to pressure sensitivity. When the crystals reached equilibrium, a new base line was established; all calculations were made from this base.

These experiments were begun in the simplest possible manner, since backstreaming of diffusion pumps seemed to be a familiar phenomenon. The chamber was evacuated to the $10^{-7}$ torr range, and the supply of $\mathrm{LN}_{2}$ to the baffle was stopped. After 20 hours, there was no sign of mass accretion on the crystals, or degradation of mirror reflectivity. This procedure was repeated three times without the slightest evidence that oil was backstreaming from the pump. It seemed that the mere interposition of a chevron baffle was sufficient barrier to backstreaming to reduce the rate to less than $10^{-9} \mathrm{gms} \mathrm{cm}^{-2}$ every 20 hours.

A heated stainless-steel cell containing DC 704 was then introduced into the vacuum system to provide oil vapor. The walls of the chamber became covered with oil; it was then unnecessary to continue to use the cell, since re-evaporation generated sufficient vapor. At 5-microns pressure, oil evaporated from the walls to the crystals at about the mass equivalent of one-fourth monolayer per hour. At $10^{-6}$ torr the deposition rate had increased to about one monolayer perhour. Experiments soon showed that this rate of deposition was invariant for pressures of $10^{-5}$, $10^{-6}$, or $10^{-7}$ torr, within existing measurement capability.

During this work, it was desirable to deposit 10 or more monolayers on mirrored surfaces in the course of one working day. The reservoir cell was heated to increase the available amount of vapor; deposition was monitored with the microbalance; and, when the desired mass was de-' posited, the chamber was backfilled with $\mathrm{N}_{2}$ to 100 microns. When the mirrors were removed, a film of oil was seen; this was removed and checked by infrared analysis to ensure that only DC 704 was being deposited. When time was not an important factor, the slower method for depositing a contaminant was used: allowing the oil deposited on the chamber walls to be a source for the 
vapor. Under these conditions, a point was reached where the crystals indicated a loss in mass, i.e., re-evaporation: exposed mirrors, when left in the vacuum overnight, were clear to visual inspection and upon test, showed little or no degradation of reflectance at $1216 \AA$. Examination of a filmed mirror with the metallographic microscope showed the oil in the form of small, discrete droplets. Figure 1 is a photomicrograph of a mirror surface on which 20 monolayer mass equivalents had been deposited in 4 hours.

To view the re-evaporation phenomenon two experiments were undertaken. Twenty monolayers were evaporated onto the open crystal of the microbalance in one chamber. The microbalance was then transferred to another chamber, so that no further contamination would occur, and the oil allowed to evaporate. Figure 2 is the record produced during this evaporation: the slope of the line shows a decreasing mass. The average rate described by the record is $6 \times 10^{-9} \mathrm{gm} / \mathrm{min} / \mathrm{cm}^{2}$. Next, approximately

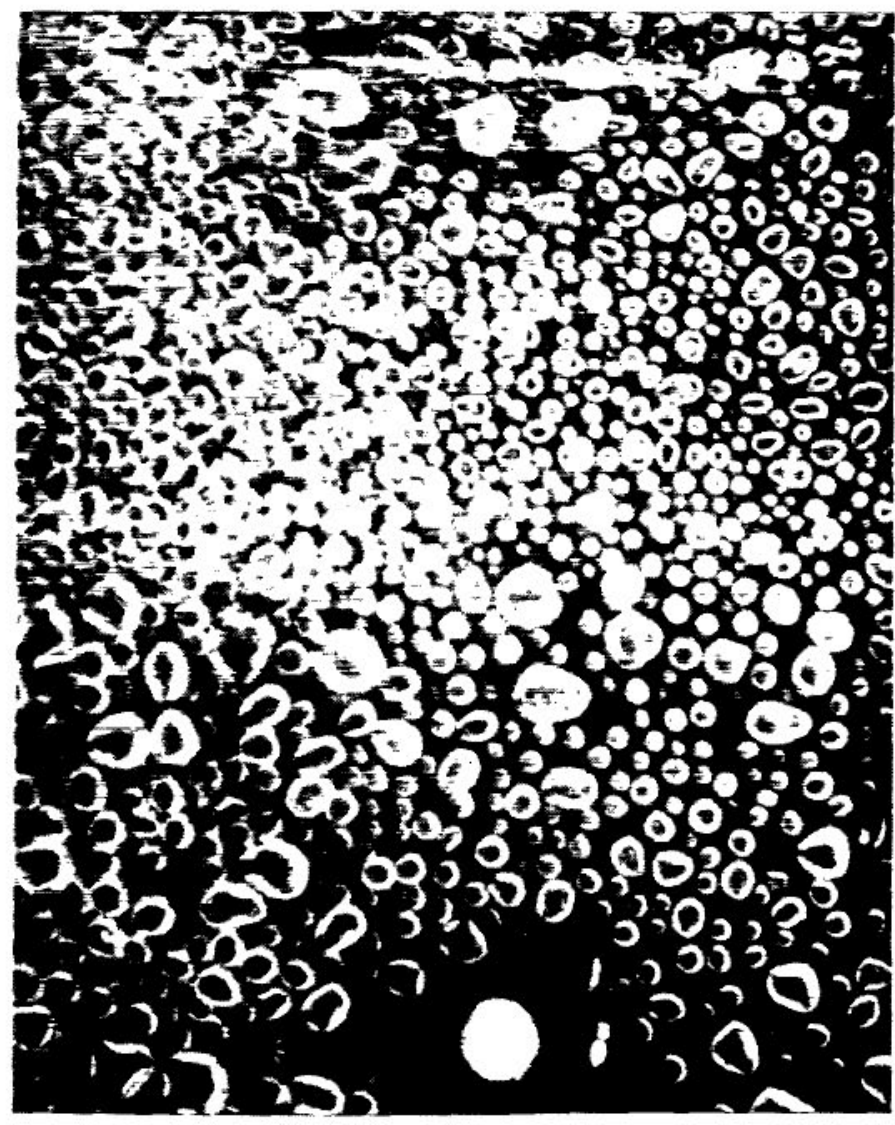

Figure 1-Approximately 20 monolayers on mirrored surface (250X magnification). 10 monolayer mass equivalents were evaporated onto a glass slide; a microscope was placed inside a vacuum chamber, and the image was projected through a window to the ground-glass back of a camera.

The sequence of photomicrographs (Figures 3 through 11) illustrates the gradual evaporation of the oil. Note that the oil droplets do not become perceptibly smaller in diameter, but they become thinner and gradually disappear. The disappearance of the films deposited at slow rates is now understandable. The oil was evaporating at a rate greater than suspected from the crystal and mirror surfaces, back to the vapor phase from which it was pumped away. It now appears that there are two physically different forms of the same liquid with different physical properties.

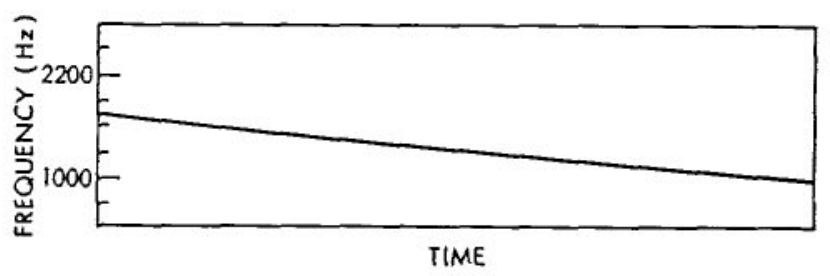

Figure 2-Microbalance record of oil re-evaporation.
It is known (Reference 1) that the vapor pressure of very small liquid droplets is much higher than that of the bulk liquid. The vapor pressure of these droplets, many of them as small as $7 \cdot 10^{-4} \mathrm{~cm}$, is much higher than the $10^{-9}$ torr ascribed to the bulk oil. It may be postulated that one mechanism of oil 


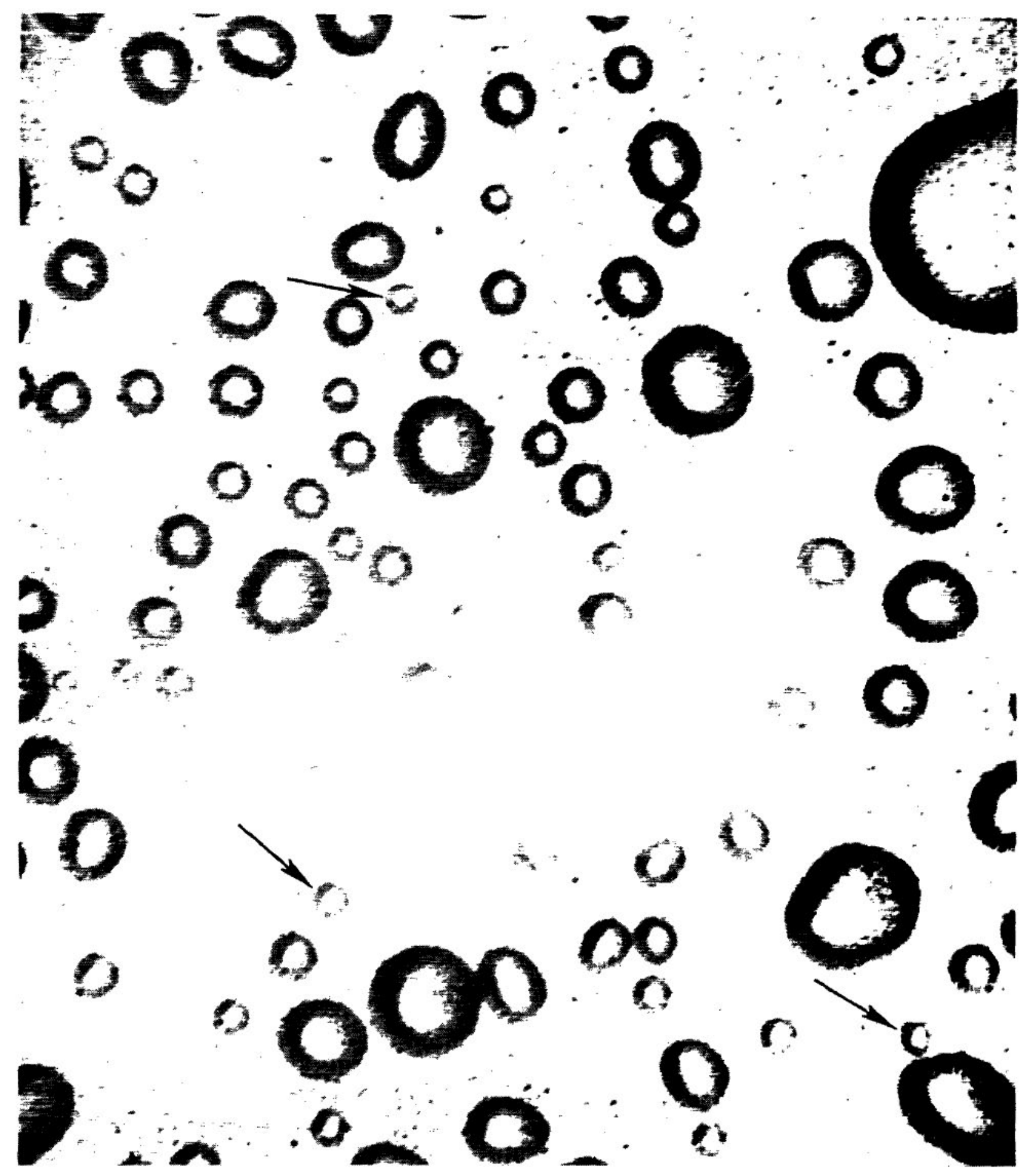

Figure 3-Ten monolayers of oil in vacuum at start of pumpdown; droplet size from 0.0003 to 0.0012 inch (350X magnification). 
$\mathbf{v}$

1

${ }^{\circ}$

, 08.00

2000.0

0.000

3

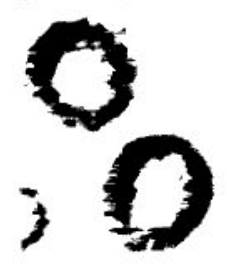

0

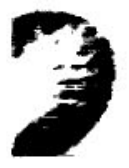

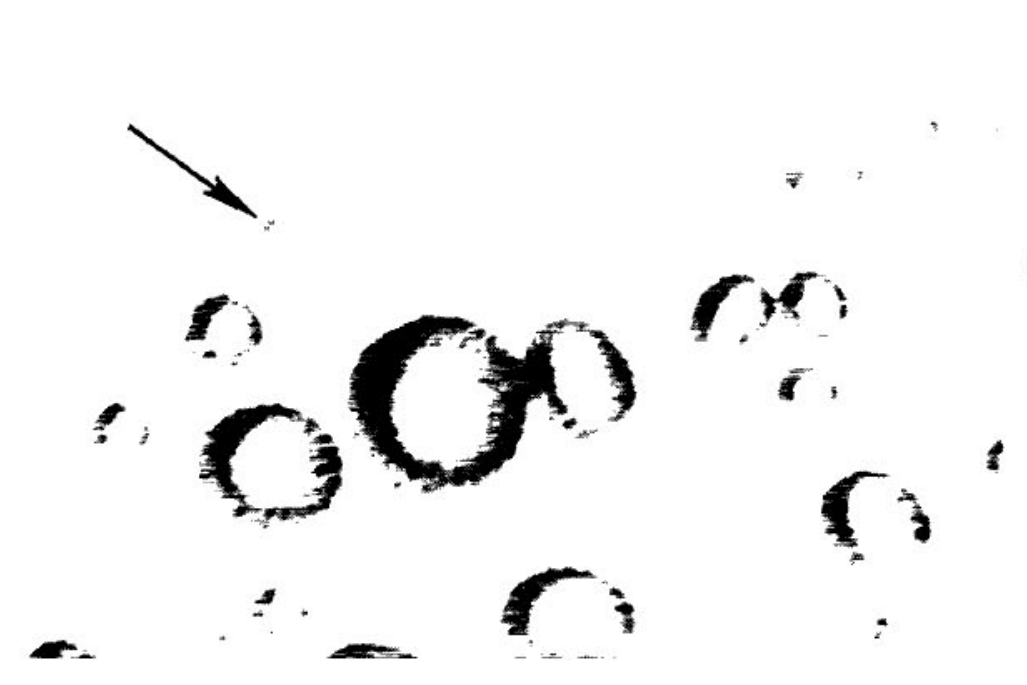

Figure 4-Droplets 3 hours after pumpdown.

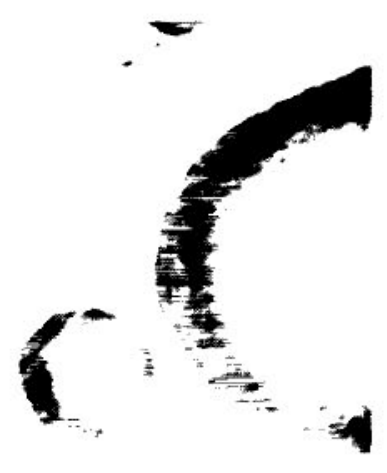

i

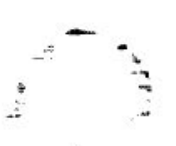

裳

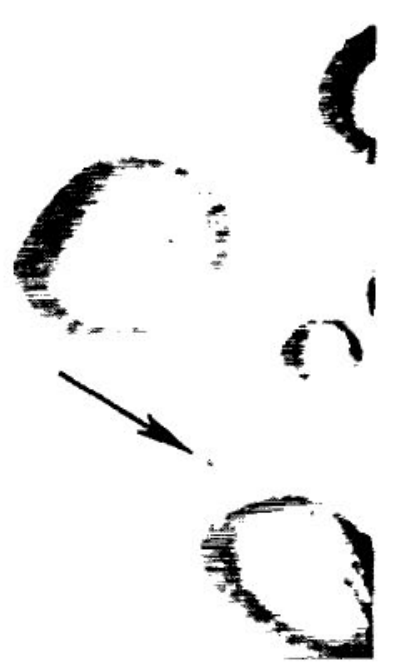




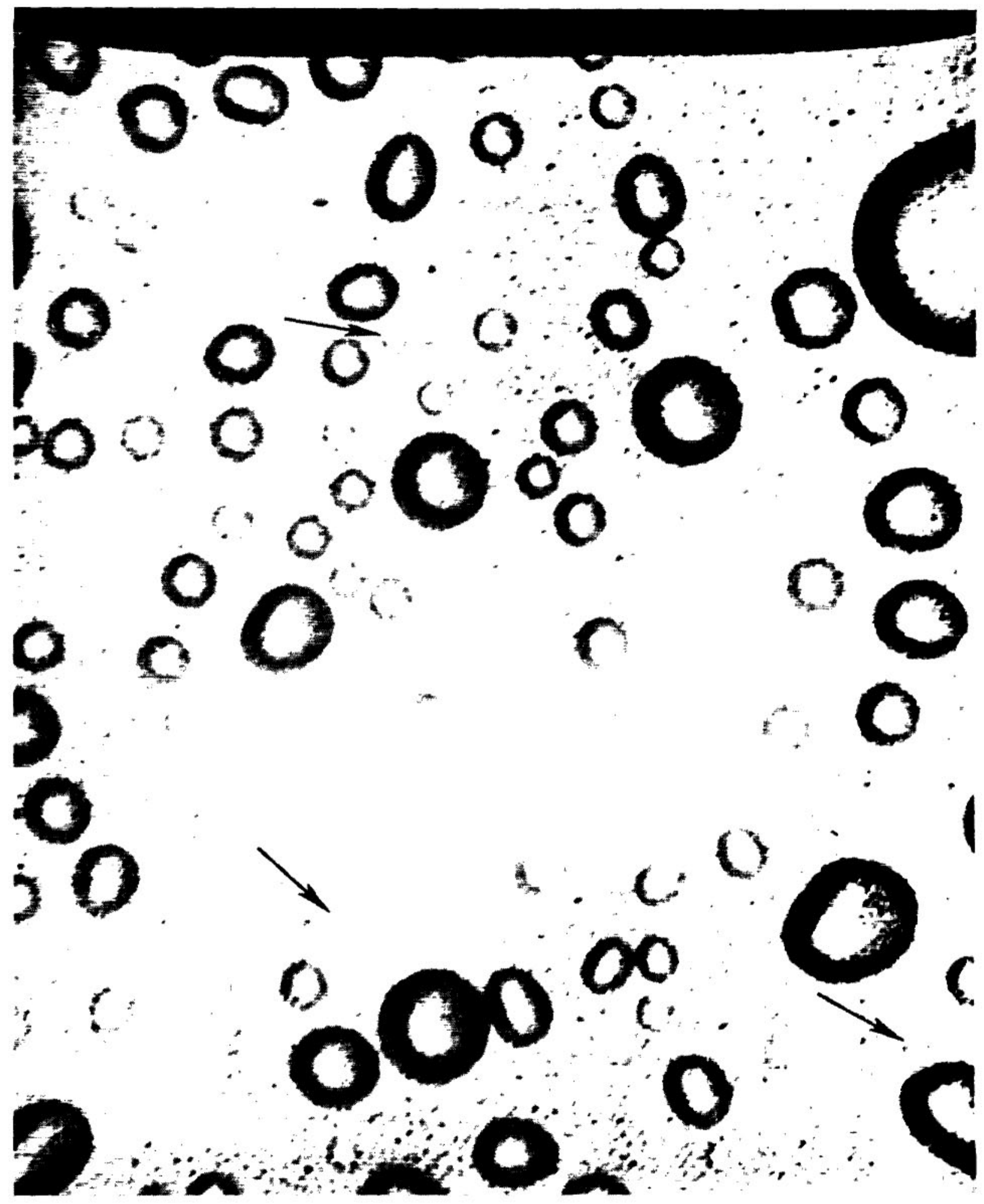

Figure 5-Droplets 4 hours after pumpdown. 


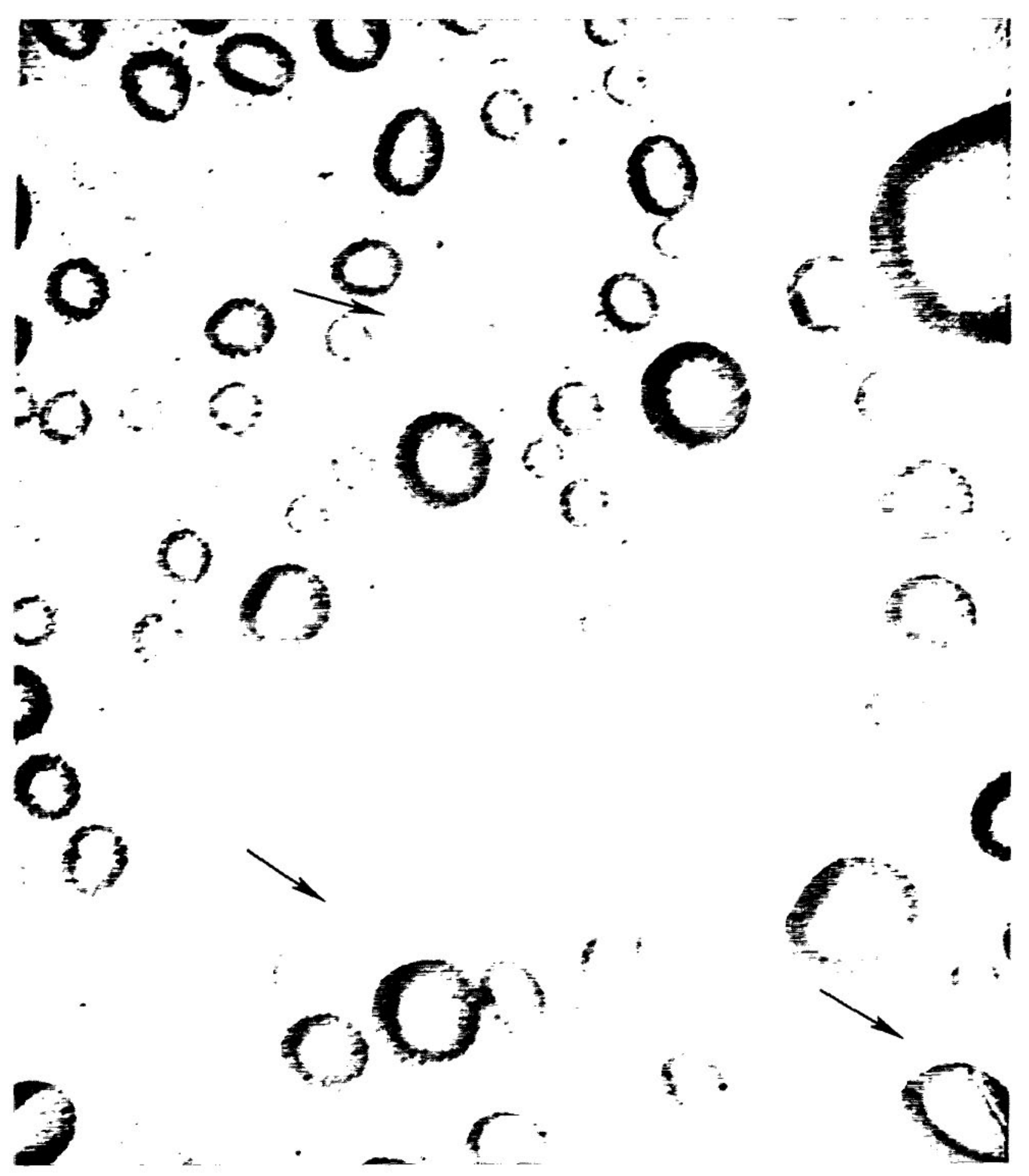

Figure 6-Droplets 5 hours after pumpdown. 


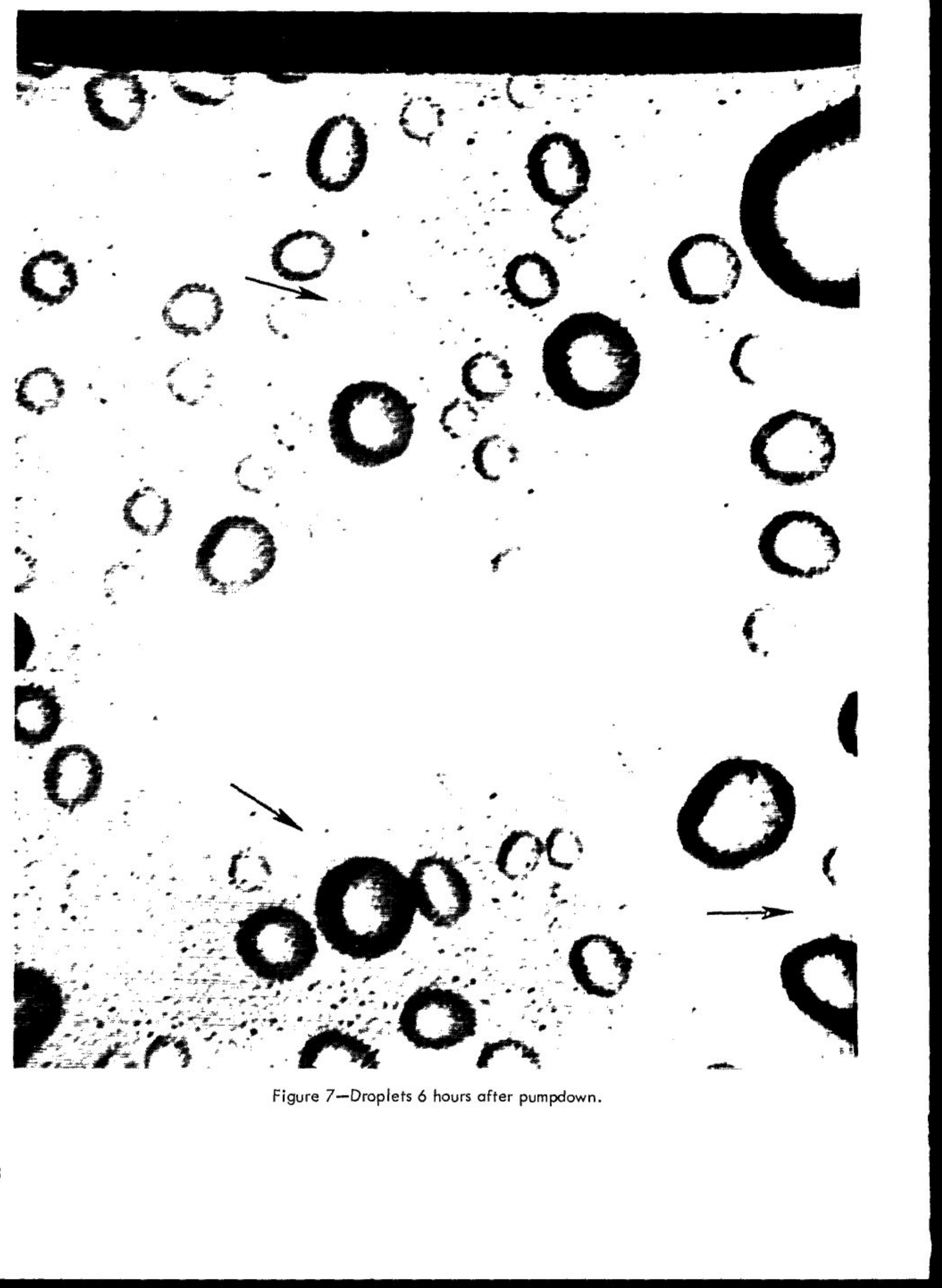





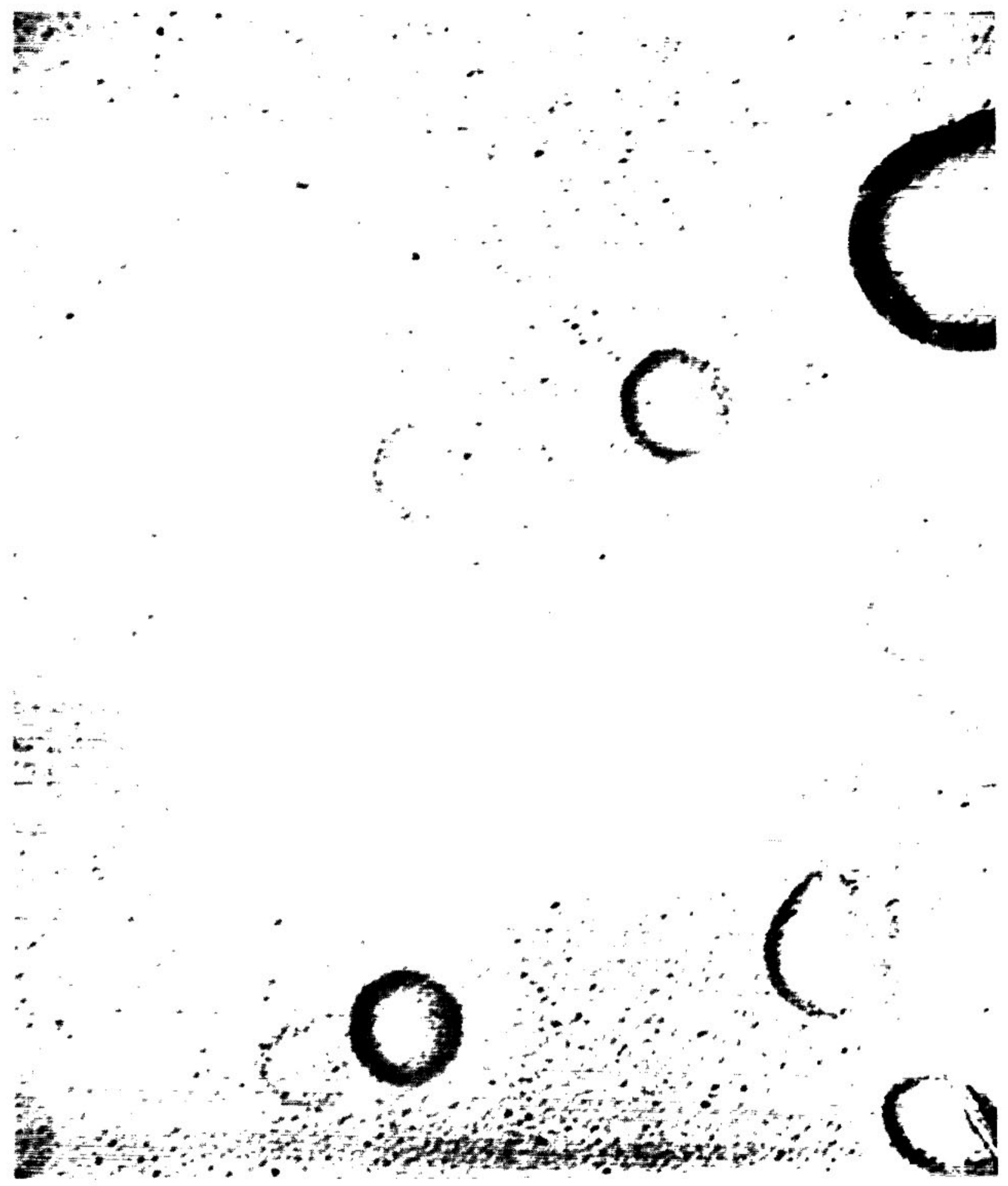

Figure 9-Droplets 24 hours after pumpdown vacuum $\left(2 \times 10^{-6}\right.$ torr $)$. 

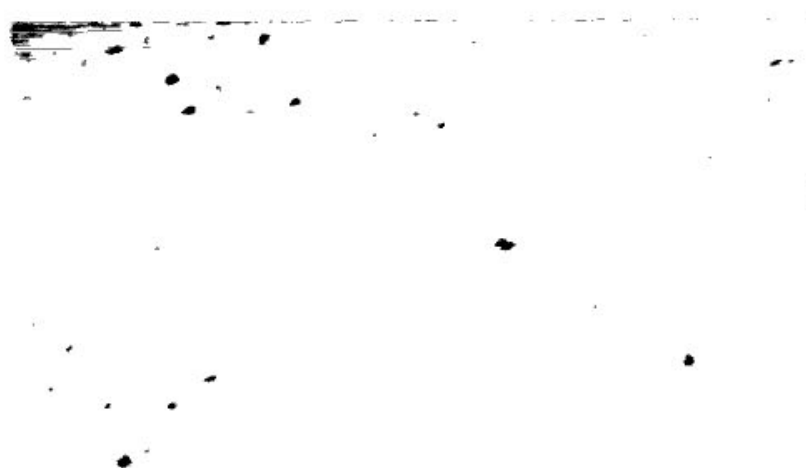

-
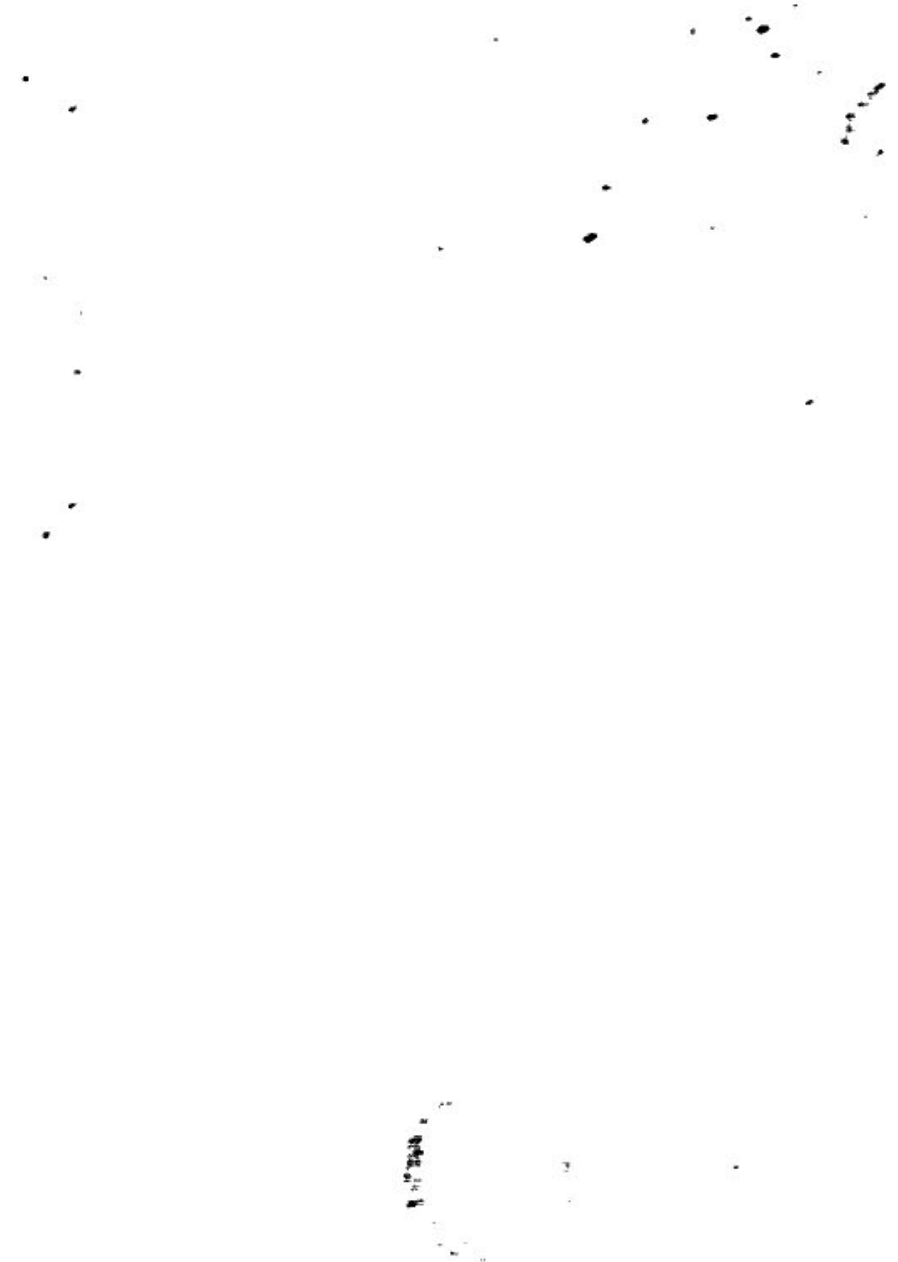

Figure 10-Droplets 28 hours after pumpdown.

11 


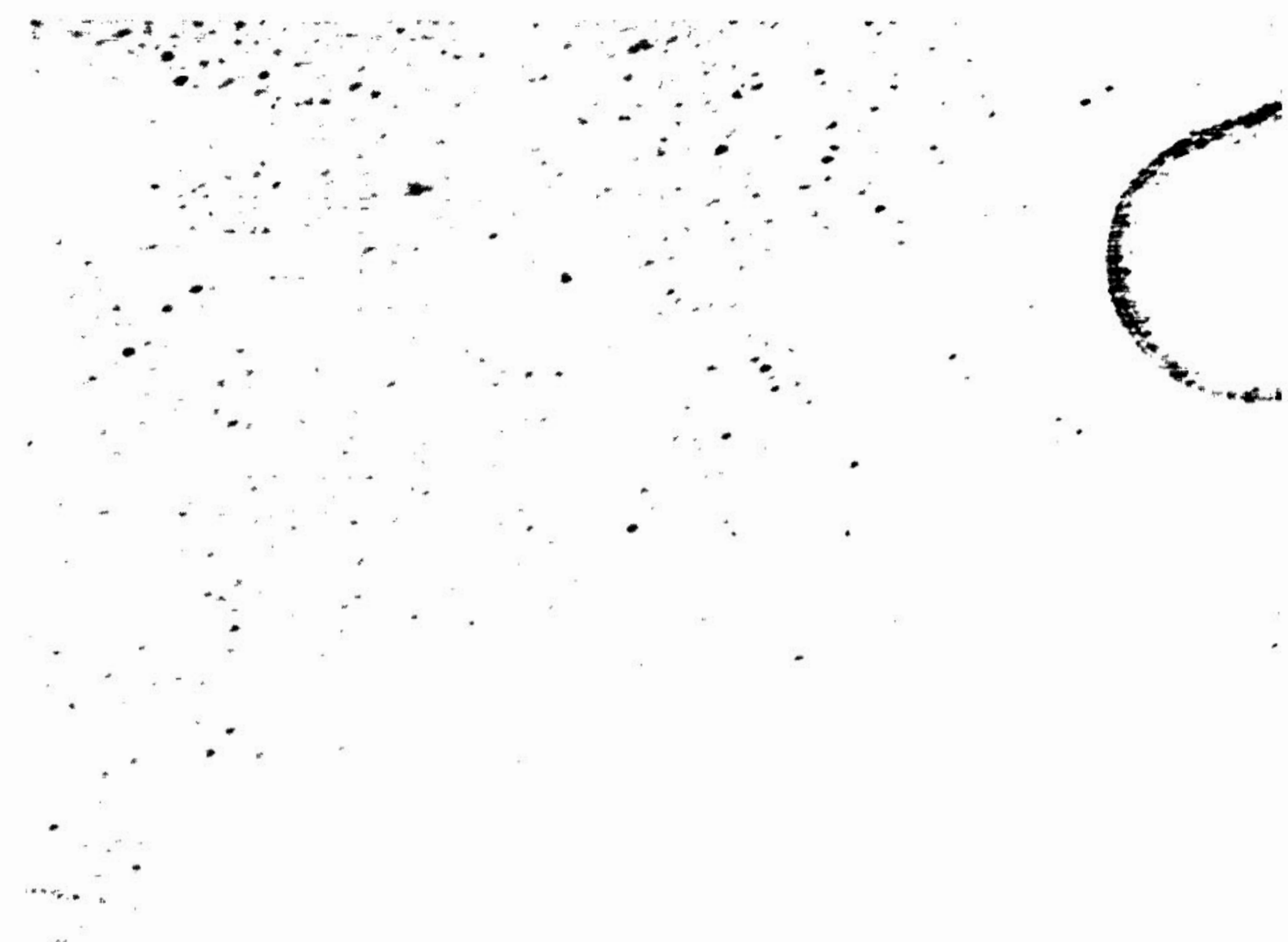

Figure 11-Droplets after 48 hours (terminal pressure $=6 \times 10^{-7}$ torr) . 
backstreaming is caused by a layer of droplets along the sides of pumps or from the undersides of traps and baffles.

As proof that the oil was re-evaporating from the sample surface, two small mirrors were prepared as targets for the electron microscope. One target was laid aside within the vacuum compartment: the other was scanned by the beam. Ennos (Reference 2) showed that bombardment of organic molecules with an electron beam desaturates and then polymerizes the molecules, fixing them in place. Figure 12 is a photograph taken with the electron microscope. The droplets shown were fixed to the surface and remained in place for at least 24 hours. The second target was examined after 24 hours. All that could be found were the two droplets shown in Figure 13.

The question then arises whether the formation of droplets is unique to glass substrates, or whether materials with widely differing surface free energies will allow films to be deposited. A slide was prepared by baking a thin film of tetrafluoroethylene and evaporating about three weightequivalent monolayers of oil on this surface. Figures 14,15, and 16 are photomicrographs of this deposit on glass, teflon, and polished stainless steel.

The objective of this research was to generate a graph that could be used by spacecraft test engineers as a guide to the amount of oil contamination acquired by optical or thermal control surfaces undergoing vacuum testing (Figure 17). The origin represents zero degradation and zero deposition. This point has an error factor amounting to approximately 2 percent degradation. Data

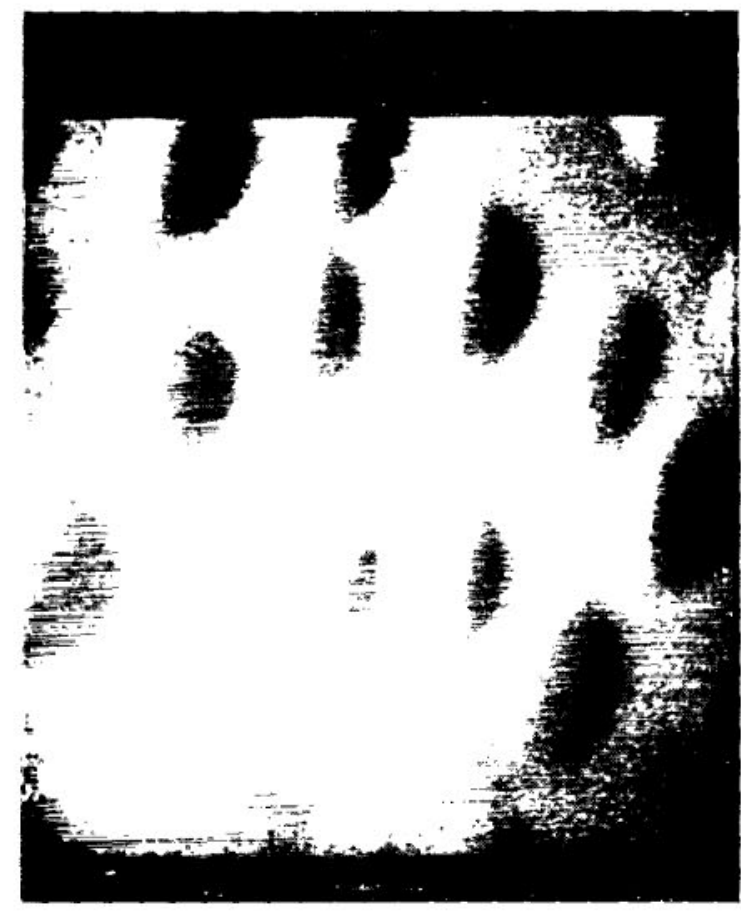

Figure 12-Ten monolayers prepared for the electron microscope (I200X magnification).

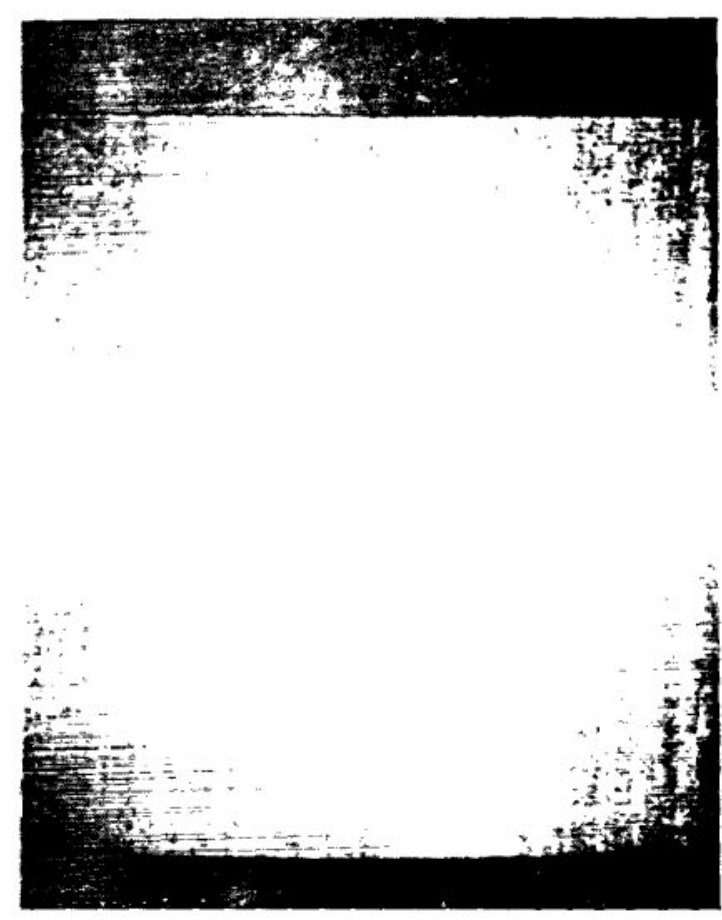

Figure 13-Ten monolayers overnight in electron beam microscope vacuum (5700X magnification). 


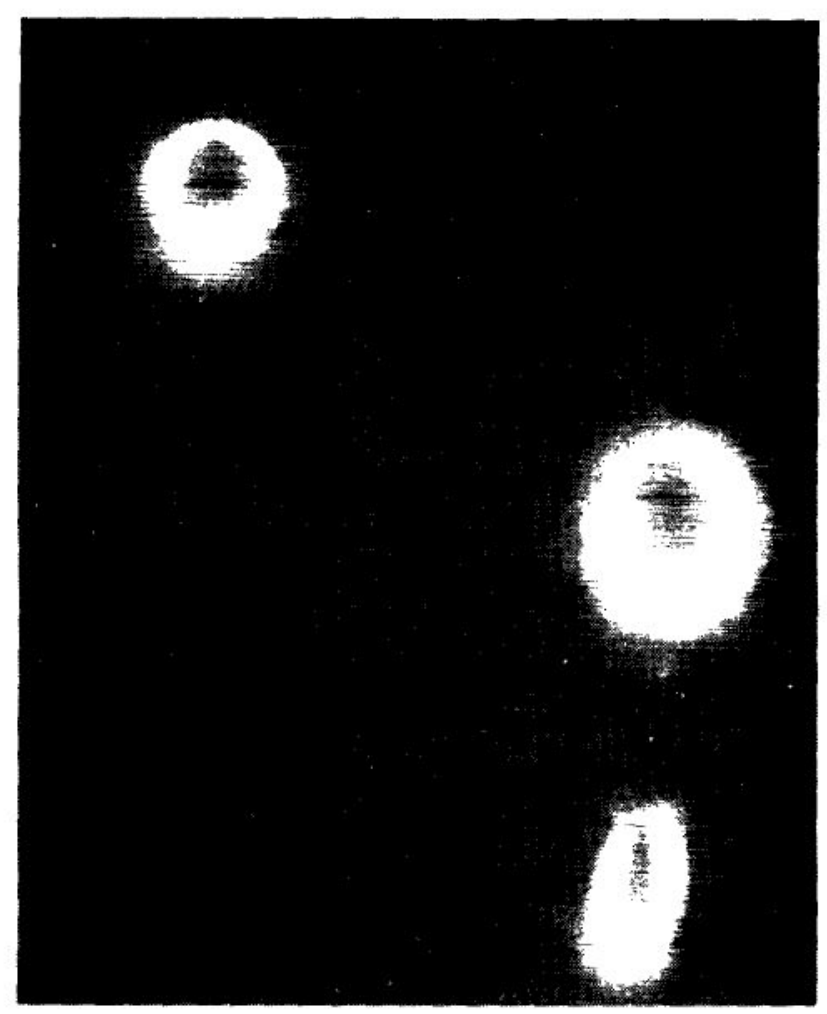

Figure 14-Three monolayers on glass by dark-field illumination; compare with Teflon and stainless steel surfaces (250X magnification).

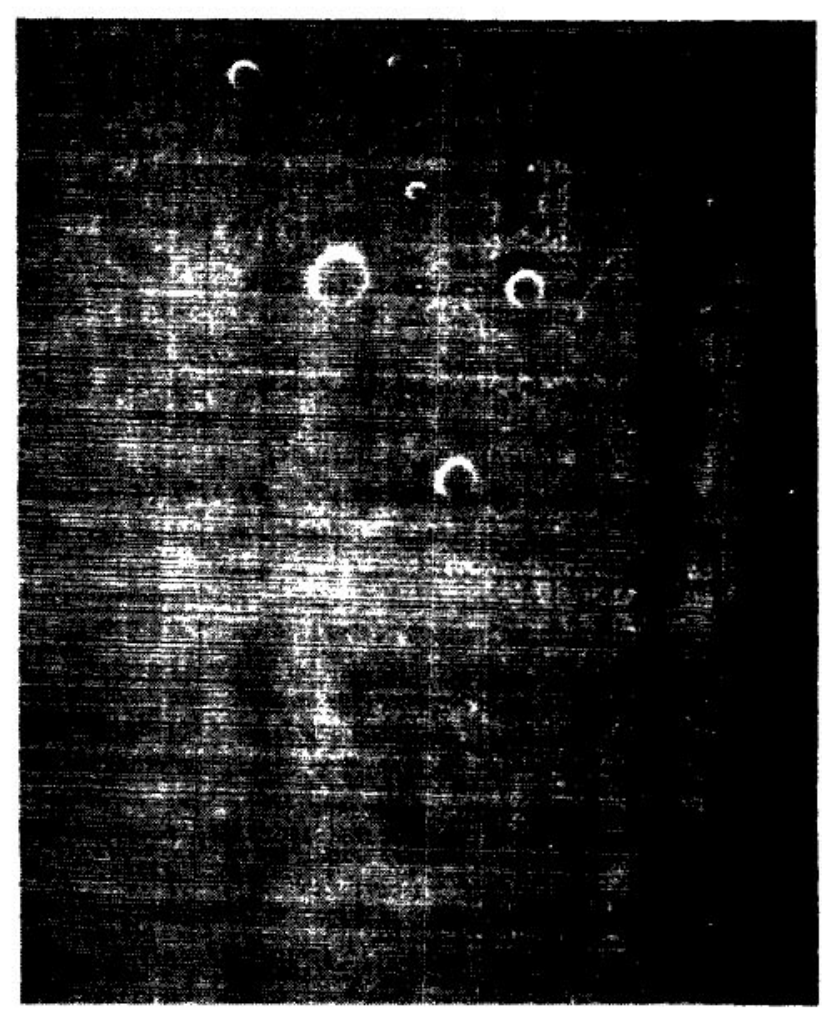

Figure 15-Three monolayers on Teflon surface by dark-field illumination (250X magnification).

in this region were highly unreliable, sometimes showing degradation and sometimes enhanced reflectivity. The remainder of the data appeared reliable and fairly repeatable.

\section{DISCUSSION AND CONCLUSIONS}

Many studies on oil backstreaming have been made, and much ingenuity has been exercised to measure the minute quantities involved. A defect of the studies is their use of averaging techniques. To obtain samples large enough to be measured, required in many instances, long periods of running times. Carter (Reference 3), using an elegant radioactive tracer technique, showed that the bulk of backstreaming occurs in the first hour after the pump has been turned on. He found that 45 minutes after the pump was turned on, the rate of backstreaming was approximately $2 \times 10^{-8} \mathrm{gm} / \mathrm{cm}^{2} / \mathrm{min}$. Langdon (Reference 4), using an ultraviolet absorption technique, measured approximately $4 \times 10^{-8} \mathrm{gm} / \mathrm{cm}^{2} / \mathrm{min}$. Holland (Reference 5), using multiple-beam interferometry, measured approximately $3 \times 10^{-8} \mathrm{gm} / \mathrm{cm}^{2} / \mathrm{min}$. These rates are so close to that of this study (e.g., $5 \times 10^{-8} \mathrm{gm} / \mathrm{cm}^{2} / \mathrm{min}$ for evaporation from the walls) that the question of chamber cleanliness arises. Others have found no backstreaming-at least under certain chosen conditions. Hablanian (Reference 6), for example, using a "wettability" test, found none; LeRiche (Reference 7) found no 


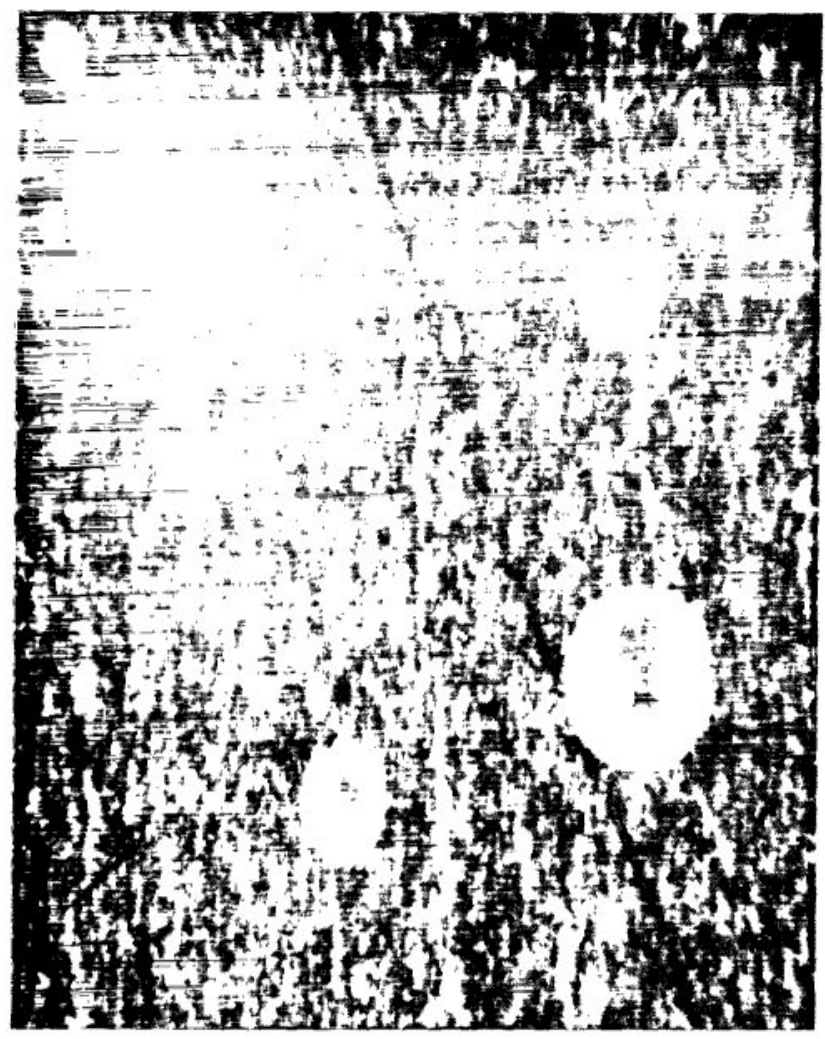

Figure 16-Three monolayers on stainless steel by dark-field illumination (250X magnification).

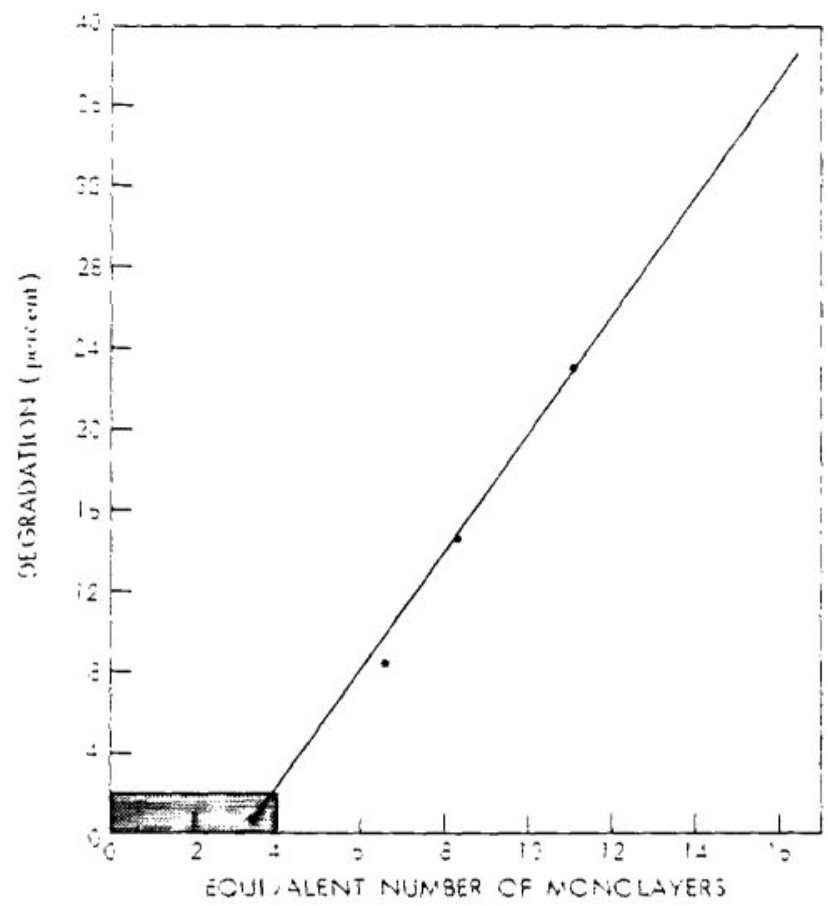

Figure 17-Percentage of degradation vs. equivalent number of monolayers.

backstreaming above a zone 18 inches from the pump throat. He describes the testing of a large solar simulator erected at Goddard Space

Flight Center. Recently, all these pumps were demounted for cleaning, and in two of the 17 pumps a band of crystalline DC 704 was found approximately 18 inches above the pump.

The experiments described in this report were performed in four chambers, which included a standard 18-inch bell jar, a stainless-steel chamber, 20- by 30-inch, a medium-sized facility, 12by 15 -foot, and finally, a large system, 40 - by 60 -foot, using mass spectrometric techniques in addition to those described here. Backstreaming occurred only in the 12- by 15-foot chamber, particularly at startup and shutdown. Investigation disclosed that an accidental discharge of oil into the chamber 2 years earlier produced the appearance of backstreaming. Subsequently, optically dense LN, baffles had been fitted across the pump orifices. The oil, having been captured in the annulus between the structural wall and the shroud, apparently could not find sufficient exit to the pumps to be removed from the chamber. It evaporated during evacuation, and some seeped into the chamber proper where it was sensed as backstreaming by a mass spectrometer and then condensed on the $\mathrm{LN}$, walls and trap covering the pump throats. Upon return to atmosphere, the walls would be warmed and the oil evaporated again giving the indication of backstreaming: however, the chamber was shut down before a significant quantity could be removed. With the quantity of oil trapped and only relatively small amounts being removed during each pumpdown, oil could appear in the chamber for a large number of operations. 
Evidently any well-designed pump, together with $\mathrm{LN}_{2}$-cooled traps, could prevent backstreaming from the pumps into the chamber. Further, if an inbleed of dry nitrogen or other such gas were maintained so that the pressure never falls below 50 microns until the diffusion pump is hot, evaporation or backstreaming should be effectively prevented. Alternatively, a valve across the mouth of the diffusion pump, opened after the pump is fully working, should be effective. In any event, in a properly operated chamber in which the deposited contamination is not too heavy, exposure to high vacuum for approximately 48 hours should result in clean surfaces.

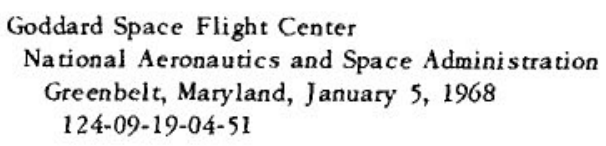

\section{REFERENCES}

1. Hulett, Z. Physikal Chem., 37:385, 1901.

2. Ennos, A. E., "The Sources of Electron-induced Contamination in Kinetic Vacuum Systems," Brit. J. Appl. Phys., 5:27-31, 1954.

3. Carter, J. G., Elder, J. A., Birkhoff, R. D., and Roecklein, A. K., "Diffusion Pump Oil Deposition Measurements Utilizing Radioactive Tracers," J. Vac. Sci. \& Tech., 2(2):59-62, 1965.

4. Langdon, W. M., Foctman, E. G., Tran. 10th Nat. Vac. Symp., 128-133, 1963.

5. Holland, L., Laurenson, L., and Priestland, C., "Contamination in Ultra High Vacuum Plant," Rev. Sci. Instr., 34(4):377, 1963.

6. Hablanian, M. H., Tran. 9th Nat. Vac. Symp., 384-389, 1962.

7. LeRiche, R. P., and Rothenberg, J. H., Tran. 9th Nat. Vac. Symp., 249-252, 1962. 
Appendix A

\section{Quartz Crystal Microbalance}

\section{Introduction}

The crystal microbalance, operating as a vacuum contamination monitor, is based on the principle that an accumulation of mass on the surface of an oscillating quartz crystal decreases its resonant frequency. Operating the crystals at cryogenic temperatures allows measurement of residuals such as carbon dioxide or water. During the course of this study, the crystals were kept at room temperature or, when the vapor reservoir was heated, at ambient water temperature. The crystal cannot differentiate between condensates, since it measures only total mass deposited. To overcome this disability, the vacuum chamber was kept free of any other source of condensable vapor. Wiring was teflon-covered: circuitry was solid-state; and supports were metal or ceramic. Two independent calibrations of the microbalance have shown a sensitivity of $10^{-9} \mathrm{gm}$ cycle of frequency shift for $10-\mathrm{MHz}$ crystals.

\section{Principle of Operation}

CRYSTAL EQUIVALENT CIRCUIT

A vibrating quartz crystal is actually an electromechanical system in which a voltage potential between the crystal terminals produces a mechanical distortion and vice-versa. However. for analytical purposes, an electrical analogy such as that in Figure $\mathrm{Al}$ is usually considered.

The impedance between terminals $\mathrm{A}$ and $\mathrm{B}$ is

$$
2 \frac{\left[R-,\left(L-\frac{1}{C_{1}}\right)\right] \frac{j}{C_{1}}}{R \cdot 1\left[L-\frac{1}{-}\left(\frac{1}{C_{n}}-\frac{1}{C_{1}}\right)\right]} .
$$

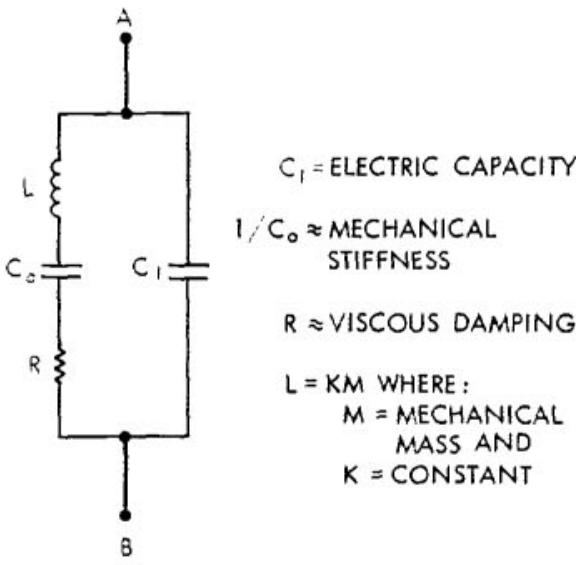

Figure Al-Crystal equivalent.

By setting the imaginary part of the denominator equal to zero and solving for , the parallel resonant frequency is obtained; hence,

$$
R=\frac{1}{\sqrt{L C_{1} C_{0} /\left(C_{1}-C_{0}\right)}}
$$


and

$$
f_{R}=2 \pi \frac{1}{\sqrt{L C}} \text {. }
$$

where

$$
C=\frac{C_{1} C_{0}}{C_{1}+C_{0}} \text {. }
$$

Since the equivalent inductance of a crystal equals the product of the crystal mass and some constant, and since all other variables remain constant, Equation A3 may be reduced to

$$
f_{R}=\frac{K_{1}}{\sqrt{m}},
$$

where $\mathrm{K}_{1}$ is a constant.

Although this relationship is nonlinear, it can be seen from the first derivative

$$
\frac{\mathrm{df}_{\mathrm{R}}}{\mathrm{dm}}=\frac{-\mathrm{K}}{\mathrm{m}^{3 / 2}}, \quad \mathrm{~K}=\text { constant } .
$$

that for small changes in mass, the relationship between frequency and mass may be considered linear.

\section{System Description}

The complete system is shown in Figure A2. Two AT-cut crystals, mounted side by side with one sealed and the other exposed, oscillate in parallel resonance. The two high-frequency signals are mixed, and the difference frequency extracted by filtering. This use of two crystals provides some temperature compensation. A change in temperature will shift the frequency of both crystals approximately by the same amount, leaving their difference frequency relatively unchanged. Also, the difference frequency (which is on the order of 1 or 2 kilohertz), is much simpler to measure and record than the approximately $10-\mathrm{MHz}$ fundamental frequency of the crystals.

Further temperature compensation is obtained during the manufacturing process. By cutting the crystals at a specified angle, a zero temperature coefficient will result at the required operating temperature of the microbalance. Cutting the crystal at $39^{\circ} 49^{\prime}$ results in a zero temperature coefficient at $-196^{\circ} \mathrm{C}$, the temperature of liquid nitrogen. Cutting at approximately $35^{\circ} 30^{\prime}$ gives a zero point at room temperature. 

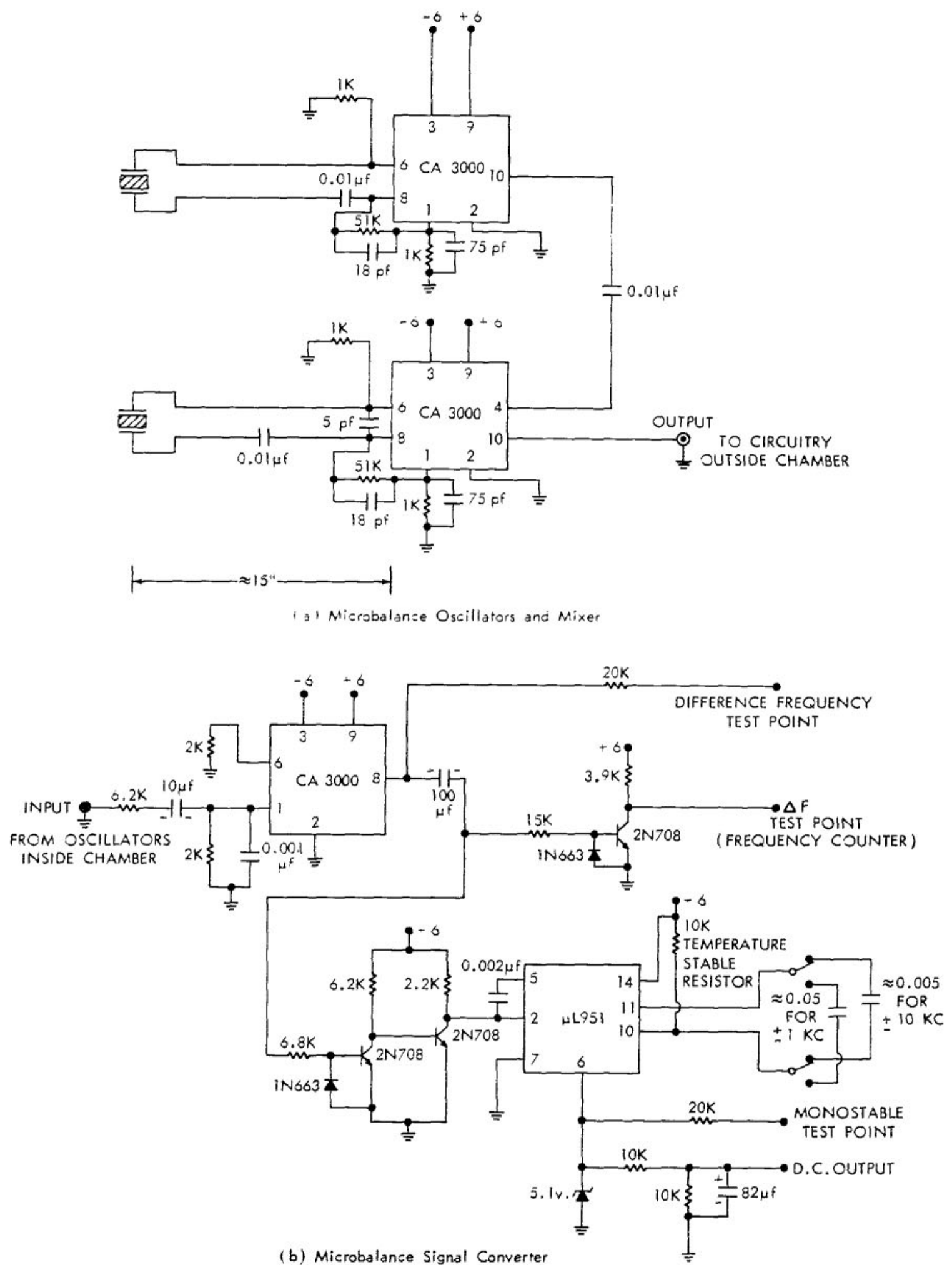

Figure A2-Complete microbalance system. 
Both the crystals and the oscillators are located inside the vacuum chamber. The crystals are mounted approximately 15 inches from the circuitry, permitting cryogenic cooling of the crystals but allowing the electronics to be maintained at room temperature. Originally, only the crystals were placed in the chamber; this restricted the microbalance to a few positions in small chambers. With the oscillators and mixer placed in the chamber, only the low-frequency differ ence signal is returned, and cable length is not a problem.

The first stage of electronics outside the chamber amplifies the signal. The signal is buffered for readout on a frequency counter. A frequency-to-voltage converter (consisting of an integrated circuit monostable multivibrator, zener reference diode, and voltage-averaging circuit) provides a dc output voltage for a recorder.

The CA3000 dc amplifier used in the oscillators and first-stage amplifier is an integratedcircuit, dc differential amplifier. The schematic diagram of this standard circuit is shown in Figure A3.

\section{Calibration}

A calibration procedure was developed for the microbalance. Basically, this procedure consisted of a modified version of the normal vacuum-plating process. The exposed crystal was mounted directly behind a $3 / 4$-inch hole drilled in a 2-inch-square aluminum plate. Aluminum disks with small holes of known area were placed in the $3 / 4$-inch hole. The aluminum plate and two glass slides were placed on a mount inside the vacuum chamber, approximately 18 inches directly above the evaporation source. An analytic microbalance measured the mass collected on the plates. This amount, together with the ratio of the disk hole area to the total surface area, determined the mass collected on the crystals. Indium was chosen as the calibrating metal because its "relatively low" evaporating temperature permitted more control of evaporation rate than would have been possible with a more common element such as aluminum.

Four evaporation runs were made for the 10- $\mathrm{MHz}$ crystals. The results are shown in

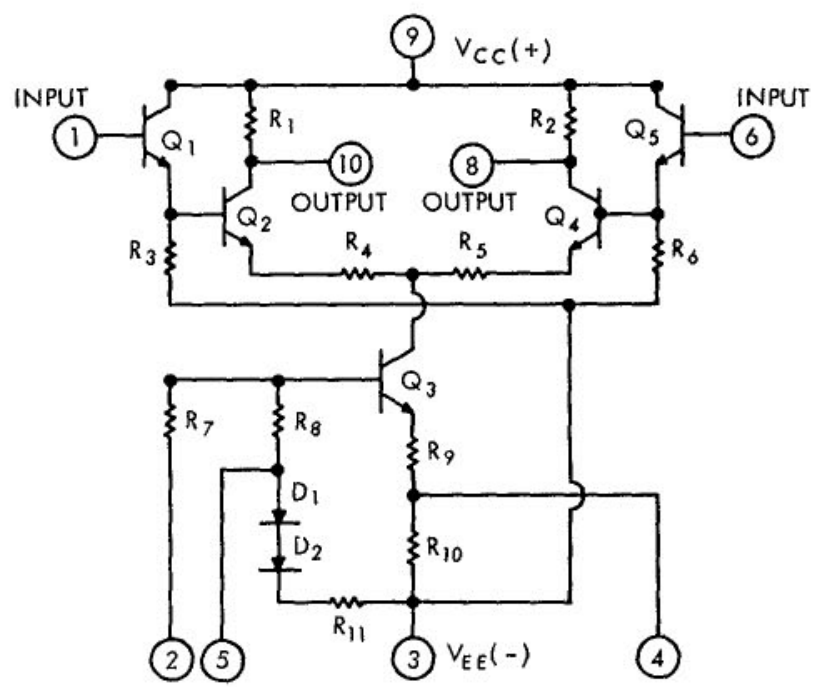

Figure A3-CA3000 dc amplifier.

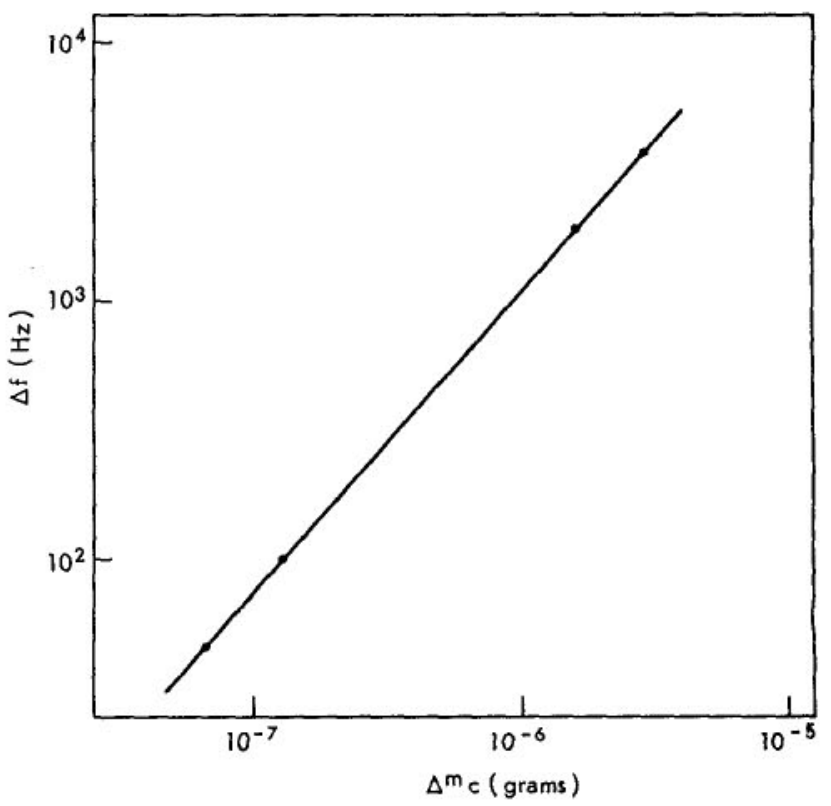

Figure A4-Quartz crystal microbalance calibration. 
Figure A4. The crystals had a sensitivity of approximately $1 \cdot 10^{-9} \mathrm{gm} / \mathrm{Hz}$. The microbalance was linear for total mass accumulation not exceeding $2 \cdot 10^{-5} \mathrm{gram}$.

The major problem encountered during calibration was temperature rise induced by indium evaporation. The sensing crystal was exposed directly to the thermal radiation of the heated source. The reference crystal was shielded to prevent it from collecting any indium. A trial run was made to find the effect of this induced temperature differential on the output frequency. Allowing the crystals to stabilize for 15 minutes caused an error of less than 0.2 percent.

A second calibration was performed during this contamination study. The method was similar to the first except that oil was used instead of indium. Within the instrument error of the mechanical balance, the initial calibration results were confirmed. 
"The aeronautical and space activities of the United States shall be conducted so as to contribute. . . to the expansion of buman knowledge of phenomena in the atmosphere and space. The Administration shall provide for the widest practicable and appropriate dissemination of information concerning its activities and the results thereof."

\section{NASA SCIENTIFIC AND TECHNICAL PUBLICATIONS}

TECHNICAL REPORTS: Scientific and technical information considered important, complete, and a lasting contribution to existing knowledge.

TECHNICAL NOTES: Information less broad in scope but nevertheless of importance as a contribution to existing knowledge.

\section{TECHNICAL MEMORANDUMS:}

Information receiving limited distribution because of preliminary data, security classification, or other reasons.

CONTRACTOR REPORTS: Scientific and technical information generated under a NASA contract or grant and considered an important contribution to existing knowledge.
TECHNICAL TRANSLATIONS: Information published in a foreign language considered to merit NASA distribution in English.

SPECIAL PUBLICATIONS: Information derived from or of value to NASA activities. Publications include conference proceedings, monographs, data compilations, handbooks, sourcebooks, and special bibliographies.

\section{TECHNOLOGY UTILIZATION}

PUBLICATIONS: Information on technology used by NASA that may be of particular interest in commercial and other non-aerospace applications. Publications include Tech Briefs, Technology Utilization Reports and Notes, and Technology Surveys.

Details on the availability of these publications may be obtained from:

SCIENTIFIC AND TECHNICAL INFORMATION DIVISION

NATIONAL AERONAUTICS AND SPACE ADMINISTRATION Washington, D.C. 20546 